\title{
Primary bone tumours of the thoracic skeleton: an audit of the Leeds regional bone tumour registry
}

\author{
David A Waller, Raymond J Newman
}

\begin{abstract}
An audit of the Leeds regional bone tumour registry found that primary bone tumours of the thoracic skeleton constituted 90 of the 2004 cases (4.5\%). Thirty seven per cent occurred in the ribs, $32 \%$ in the scapulae, $11 \%$ in the thoracic vertebrae, $11 \%$ in the sternum, and $9 \%$ in the clavicles. Malignant tumours were more common than benign (54 $v 36)$ and occurred in an older population (mean ages 47 and 31 years). The scapula was the most common site for malignant lesions and the ribs the most common site for benign tumours. Chondrosarcoma was the commonest tumour in older patients, fibrous dysplasia and plasmacytoma in the middle age group, and eosinophilic granuloma in children. Presenting symptoms were a poor guide to whether the lesion was malignant or not. This and the small proportion of correct preoperative diagnoses indicate the need for early biopsy. Bone tumour registries provide a valuable source of cumulative information about uncommon tumours and facilitate accurate diagnosis, teaching, and research.
\end{abstract}

As primary bone tumours are uncommon the experience of individual clinicians is limited, often leading to delay in diagnosis and suboptimal management. For this reason physicians, surgeons, and pathologists in several regions have established bone tumour registries. The accumulated data provide a valuable source of information for research, education, and clinical practice.

Primary tumours of the thoracic skeleton are rare, accounting for only $7-8 \%$ of published series of primary bone tumours. ${ }^{12}$ This review audits the experience of the Leeds regional bone tumour registry with regard to tumours of the ribs, sternum, scapulae, clavicles, and thoracic vertebrae. Previous series of thoracic wall tumours have been restricted to certain sites, such as the ribs and sternum, ${ }^{1-3}$ and only one previous paper has included all the bones of the thoracic skeleton. ${ }^{4}$

\section{Methods}

The Leeds regional bone tumour registry was established by the orthopaedic and pathology departments at St James's University Hospital, Leeds, in 1958 and 2004 cases of primary bone tumour have been contributed by consultants of all disciplines within the North Yorkshire, West Yorkshire, and Humberside regions. The final diagnosis is agreed only after a review of the clinical, radiological, and histological details at multidisciplinary audit meetings. Doubtful cases are referred to the National Bone Tumour Panel. Summarised clinical data, radiographs, and histological slides are catalogued in chronological order. All cases are reviewed by the registrar at least every five years to maintain up to date clinical details and to review the diagnoses in the light of new information and classifications. Referring clinicians are encouraged to notify the registrar of the subsequent clinical progress of their patients.

The data on all cases concerning the thoracic skeleton were reviewed to obtain cumulative details of presentation, treatment, and survival.

\section{ANALYSIS}

The unpaired Student's $t$ test was used to assess the statistical significance of the difference in age of patients with benign and malignant tumours.

\section{Results}

Ninety primary bone tumours arising in the thoracic skeleton were recorded $(4.5 \%$ of all cases in the registry). Thirty three occurred in the ribs, 29 in the scapulae, 10 in the sternum, 10 in the thoracic vertebrae, and eight in the clavicle (table 1). There was no right or left predominance. The clinical features of the patients, their diagnoses, and the sites of the tumours are presented in tables 1-4.

There were 57 men and 33 women, with an overall mean age of 40.6 (range 2-86) years. Malignant tumours were more common than benign (54:36) and occurred in a significantly older population than benign lesions (mean ages $46.8 v 30.9$ years; $p<0.001$ ).

Chondrosarcoma was the most common tumour in the thoracic skeleton $(24 \%$ of all tumours); survival from this tumour was better than for osteosarcoma and fibrosarcoma (table 3). The scapula was the most common site of malignant tumours whereas most benign tumours occurred in the ribs (table 1).

Operative resection was attempted in 64 of 
the 90 patients-in 37 with a malignant tumour and in 27 with a benign tumour. Tumours recurred in 21 cases after resection, including one benign tumour (chondroma). Twenty three patients, all but two of whom had a malignant tumour, died during the 32 year period under review.

\section{THE SITES OF THE TUMOURS}

Ribs

The ribs were the most frequently affected bones in the thoracic skeleton and the tumours were distributed in an apparently random pattern. Thirty three cases $(21$ male, 12 female; mean age 38 (range 2-70) years) were recorded; fibrous dysplasia was the most common diagnosis (table 1). Benign tumours were the more common overall $(55 \%$ of cases).

The most common presenting symptom was local chest pain (18 patients); a mass was palpable in 12 patients and two tumours (osteoclastoma and plasmacytoma) were discovered as incidental findings on a routine chest radiograph.

A correct diagnosis based on clinical and radiological grounds was made in only three cases. In the other cases the diagnosis was either incorrect or no definitive diagnosis was made. The lesion was biopsied in nine patients; four subsequently received radiotherapy alone and one (with fibrous dysplasia) no further treatment. Twenty eight patients underwent rib resection. Seven tumours recurred, most commonly chondrosarcoma, of

Table 1 Distribution of primary bone tumours of the thoracic skeleton

\begin{tabular}{|c|c|c|c|c|c|c|}
\hline Tumour type & Scapula & Ribs & Sternum & Vertebrae & Clavicles & Total \\
\hline \multicolumn{7}{|l|}{ MALIGNANT } \\
\hline Chondrosarcoma & 7 & 7 & 6 & 2 & 0 & 22 \\
\hline Fibrosarcoma & 7 & 0 & 1 & 0 & 0 & 8 \\
\hline Osteosarcoma & 2 & 3 & 0 & 1 & 1 & 7 \\
\hline Plasmacytoma & 0 & 2 & 1 & 1 & 1 & 5 \\
\hline Reticulosarcoma & 1 & 2 & 0 & 0 & 2 & 5 \\
\hline Ewing's sarcoma & 4 & 1 & 0 & 0 & 0 & 5 \\
\hline Clear cell sarcoma & 0 & 0 & 0 & $\mathbf{0}$ & 1 & 1 \\
\hline Hodgkin's lymphoma & 0 & 0 & 1 & $\mathbf{0}$ & 0 & 1 \\
\hline Subtotal & 21 & 15 & 9 & 4 & 5 & 54 \\
\hline \multicolumn{7}{|l|}{ BENIGN } \\
\hline Fibrous dysplasia & 0 & 8 & 0 & 0 & 0 & 8 \\
\hline Chondroma & 1 & 4 & 1 & 1 & 0 & 7 \\
\hline Eosinophilic granuloma & 3 & 1 & 0 & 1 & 1 & 6 \\
\hline Osteochondroma & 3 & 1 & 0 & 0 & 0 & 4 \\
\hline Osteoclastoma & 0 & 2 & 0 & 1 & 0 & 3 \\
\hline Osteoid osteoma & 1 & 1 & 0 & 0 & 0 & 2 \\
\hline Aneurysmal bone cyst & 0 & 0 & 0 & 1 & 1 & 2 \\
\hline Haemangioma & 0 & 1 & 0 & 1 & 0 & 2 \\
\hline Lymphangioma & 0 & 0 & 0 & $\mathbf{0}$ & 1 & 1 \\
\hline Osteoblastoma & 0 & 0 & 0 & 1 & 0 & 1 \\
\hline Subtotal & 8 & 18 & 1 & 6 & 3 & 36 \\
\hline Total & 29 & 33 & 10 & 10 & 8 & 90 \\
\hline Mean age (y) & $35 \cdot 9$ & $37 \cdot 7$ & $59 \cdot 1$ & $43 \cdot 6$ & $42 \cdot 3$ & $40 \cdot 6$ \\
\hline Range (y) & $(2-78)$ & $(2-70)$ & $(26-86)$ & $(9-77)$ & $(12-76)$ & $(2-86)$ \\
\hline
\end{tabular}

Table 2 Preoperative details

\begin{tabular}{|c|c|c|c|c|c|c|}
\hline \multirow[b]{2}{*}{ Tumour type } & \multirow[b]{2}{*}{$n$} & \multirow[b]{2}{*}{$M: F$} & \multicolumn{3}{|c|}{ Presentation } & \multirow{2}{*}{$\begin{array}{l}\text { Correct } \\
\text { preoperative } \\
\text { diagnosis }\end{array}$} \\
\hline & & & Mass & Pain & $\begin{array}{l}\text { Incidental } \\
\text { finding }\end{array}$ & \\
\hline \multicolumn{7}{|l|}{ MALIGNANT } \\
\hline Chondrosarcoma & 22 & $12: 10$ & 17 & 8 & 0 & 2 \\
\hline Fibrosarcoma & 8 & $4: 4$ & 6 & 3 & 0 & 0 \\
\hline Osteosarcoma & 7 & $7: 0$ & 3 & 6 & 0 & 1 \\
\hline Plasmacytoma & 5 & 5:0 & 0 & 2 & 1 & 0 \\
\hline Reticulosarcoma & 5 & $3: 2$ & 3 & 2 & 0 & 0 \\
\hline Ewing's sarcoma & 5 & $4: 1$ & 2 & 4 & 0 & 0 \\
\hline Clear cell sarcoma & 1 & $1: 0$ & 0 & 1 & 0 & 0 \\
\hline Hodgkin's lymphoma & 1 & $0: 1$ & 1 & 0 & 0 & 0 \\
\hline Subtotal & 54 & $36: 18$ & 32 & 26 & 1 & 3 \\
\hline \multicolumn{7}{|l|}{ BENIGN } \\
\hline Fibrous dysplasia & 8 & $6: 2$ & 1 & 7 & 0 & 0 \\
\hline Chondroma & 7 & $4: 3$ & 4 & 4 & 0 & 2 \\
\hline Eosinophilic granuloma & 6 & $5: 1$ & 2 & 3 & 1 & 0 \\
\hline Osteochondroma & 4 & $1: 3$ & 3 & 0 & 1 & 1 \\
\hline Osteoclastoma & 3 & $2: 1$ & 1 & 2 & 1 & 0 \\
\hline Osteoid osteoma & 2 & $1: 1$ & 0 & 2 & 0 & 1 \\
\hline Aneurysmal bone cyst & 2 & $2: 0$ & 0 & 2 & 0 & 0 \\
\hline Haemangioma & 2 & $0: 2$ & 0 & 1 & 1 & 0 \\
\hline Lymphangioma & 1 & $0: 1$ & 0 & 0 & 1 & 0 \\
\hline Osteoblastoma & 1 & $0: 1$ & 0 & 1 & 0 & 0 \\
\hline Subtotal & 36 & $21: 15$ & 11 & 22 & 5 & 4 \\
\hline Total & 90 & $57: 33$ & 43 & 48 & 6 & 7 \\
\hline
\end{tabular}


which two had further resection. There were five tumour related deaths during the period of the study at a mean interval of 19 months from presentation.

\section{Scapula}

The 29 cases affecting the scapulae (19 males, 10 female; mean age 36 (range 2-78) years) constituted almost one third of all tumours in this series (table 1). Most of the tumours were malignant and occurred in an older population than the benign lesions (mean (SD) age 41.4 $(22.5) v 15.8(12.5)$ years; $p<0.001)$. Chondrosarcoma and fibrosarcoma were the most frequent diagnoses (seven cases each). Most tumours presented with a mass (59\%), but $48 \%$ presented with local chest wall pain. There was no particular site of predeliction.
The correct diagnosis based on clinical and radiological investigations was made before biopsy in only four cases. In the remaining cases no diagnosis was made or it was incorrect. Definitive treatment was performed without provisional biopsy in 10 patients, mainly for lesions suspected of being benign. Excision was performed in 21 patients, with a total scapulectomy in nine and forequarter amputation in three. Local recurrence occurred in eight patients, all with malignant tumours. The most frequently recurring tumour was fibrosarcoma. Tumour related mortality was $36 \%$ with a mean interval to death of 30 months.

Clavicle

There were only eight tumours of the clavicle,

Table 3 Postoperative details

\begin{tabular}{|c|c|c|c|c|c|c|c|}
\hline \multirow[b]{2}{*}{ Tumour type } & \multirow[b]{2}{*}{$n$} & \multirow[b]{2}{*}{ Biopsy } & \multicolumn{2}{|l|}{ Excision } & \multirow{2}{*}{$\begin{array}{l}\text { Chemotherapy/ } \\
\text { radiotherapy }\end{array}$} & \multirow[b]{2}{*}{ Recurrence } & \multirow[b]{2}{*}{ Deaths } \\
\hline & & & Subtotal & Total & & & \\
\hline \multicolumn{8}{|l|}{ MALIGNANT } \\
\hline Chondrosarcoma & 22 & 7 & 10 & 11 & 1 & 5 & 6 \\
\hline Fibrosarcoma & 8 & 7 & 4 & 3 & 1 & 7 & 5 \\
\hline Osteosarcoma & 7 & 4 & 2 & 1 & 4 & 3 & 6 \\
\hline Plasmacytoma & 5 & 3 & 2 & 0 & 5 & 0 & 0 \\
\hline Reticulosarcoma & 5 & 5 & 0 & 1 & 4 & 1 & 3 \\
\hline Ewing's sarcoma & 5 & 3 & 1 & 2 & 1 & 1 & 1 \\
\hline Clear cell sarcoma & 1 & 1 & 0 & 0 & 1 & 0 & 1 \\
\hline Hodgkin's lymphoma & 1 & 1 & 0 & 0 & 1 & 1 & 0 \\
\hline Subtotal & 54 & 31 & 19 & 18 & 18 & 18 & 22 \\
\hline \multicolumn{8}{|l|}{ BENIGN } \\
\hline Fibrous dysplasia & 8 & 1 & 3 & 4 & 0 & 0 & 0 \\
\hline Chondroma & 7 & 1 & 5 & 2 & 1 & 1 & 0 \\
\hline Eosinophilic granuloma & 6 & 6 & 0 & 0 & 2 & 0 & 0 \\
\hline Osteochondroma & 4 & 0 & 3 & 1 & 0 & 0 & 0 \\
\hline Osteoclastoma & 3 & 1 & 2 & 0 & 2 & 1 & 0 \\
\hline Osteoid osteoma & 2 & 0 & 2 & 0 & 0 & 0 & 0 \\
\hline Aneurysmal bone cyst & 2 & 1 & 2 & 0 & 1 & 0 & 0 \\
\hline Haemangioma & 2 & 0 & 1 & 0 & 0 & 0 & 0 \\
\hline Lymphangioma & 1 & 0 & 1 & 0 & 0 & 0 & 0 \\
\hline Osteoblastoma & 1 & 0 & 1 & 0 & 1 & 1 & 1 \\
\hline Subtotal & 36 & 10 & 20 & 7 & 7 & 3 & 1 \\
\hline Total & 90 & 41 & 39 & 25 & 25 & 21 & 23 \\
\hline
\end{tabular}

Table 4 Age distribution of tumours

\begin{tabular}{|c|c|c|c|c|c|c|c|}
\hline \multirow[b]{2}{*}{ Tumour type } & \multirow{2}{*}{$\begin{array}{l}\text { Mean (range) } \\
\text { age }(y)\end{array}$} & \multicolumn{6}{|c|}{ Age group } \\
\hline & & $0-15$ & $16-30$ & $31-45$ & $46-60$ & $60+$ & Total \\
\hline \multicolumn{8}{|l|}{ MALIGNANT } \\
\hline Chondrosarcoma & $53(18-86)$ & - & 5 & 3 & 6 & 8 & 22 \\
\hline Fibrosarcoma & $48(25-78)$ & - & 1 & 2 & 4 & 1 & 8 \\
\hline Osteosarcoma & $59(28-78)$ & - & 1 & - & 2 & 4 & 7 \\
\hline Plasmacytoma & $43(37-55)$ & - & - & 4 & 1 & - & 5 \\
\hline Reticulosarcoma & $33(13-76)$ & 1 & 1 & 2 & - & 1 & 5 \\
\hline Ewing's sarcoma & $14(8-23)$ & 3 & 2 & - & - & - & 5 \\
\hline Clear cell sarcoma & 72 & - & - & - & - & 1 & 1 \\
\hline Hodgkin's lymphoma & 54 & - & - & - & 1 & - & 1 \\
\hline Subtotal & $47(8-86)$ & 4 & 10 & 11 & 14 & 15 & 54 \\
\hline \multicolumn{8}{|l|}{ BENIGN } \\
\hline Fibrous dysplasia & $39(7-64)$ & 1 & - & 4 & 2 & 1 & 8 \\
\hline Chondroma & $36(19-60)$ & - & 4 & 2 & 1 & $\underline{-}$ & 7 \\
\hline Eosinophilic granuloma & $9(2-15)$ & 6 & - & - & - & - & 6 \\
\hline Osteochondroma & $19(5-35)$ & 2 & 1 & 1 & - & - & 4 \\
\hline Osteoclastoma & $38(26-53)$ & - & 1 & 1 & $\overline{1}$ & - & 3 \\
\hline Osteoid osteoma & $26(16-36)$ & - & 1 & i & - & - & 2 \\
\hline Aneurysmal bone cyst & $34(15-53)$ & 1 & - & - & 1 & - & 2 \\
\hline Haemangioma & $73(68-77)$ & - & - & - & - & 2 & 2 \\
\hline Lymphangioma & 36 & - & - & 1 & - & - & 1 \\
\hline Osteoblastoma & 9 & 1 & - & - & - & - & 1 \\
\hline Subtotal & $31(2-77)$ & 11 & 7 & 10 & 5 & 3 & 36 \\
\hline Total & $41(2-86)$ & 15 & 17 & 21 & 19 & 18 & 90 \\
\hline
\end{tabular}


Table 5 Cases in which treatment was suboptimal owing to lack of initial tissue diagnosis

\begin{tabular}{|c|c|}
\hline Original diagnosis & Histological diagnosis \\
\hline $\begin{array}{l}\text { RIB } \\
\text { Chondroma in } 39 \text { year old man on } \\
\text { radiographic and clinical examination }\end{array}$ & $\begin{array}{l}\text { Chondrosarcoma diagnosed } 10 \text { months later } \\
\text { after sudden increase in size; wide excision } \\
\text { performed }\end{array}$ \\
\hline $\begin{array}{l}\text { Chondroma in } 18 \text { year old woman on } \\
\text { radiographic and clinical examination }\end{array}$ & $\begin{array}{l}\text { Chondrosarcoma diagnosed } 12 \text { months later } \\
\text { after increase in size and pain; wide excision } \\
\text { performed }\end{array}$ \\
\hline $\begin{array}{l}\text { Chondroma in } 28 \text { year old man on } \\
\text { radiographic appearance }\end{array}$ & $\begin{array}{l}\text { Osteosarcoma subsequently diagnosed on } \\
\text { histological examination; extent of original } \\
\text { excision inadequate }\end{array}$ \\
\hline $\begin{array}{l}\text { Tuberculous abscess in } 47 \text { year old Asian } \\
\text { man on radiographic and clinical } \\
\text { examination }\end{array}$ & $\begin{array}{l}\text { Chondrosarcoma diagnosed on histological } \\
\text { examination when the patient did not } \\
\text { respond to medical treatment; excision was } \\
\text { inadequate and the patient refused further } \\
\text { surgery and died } 2 \text { years later with } \\
\text { metastatic disease }\end{array}$ \\
\hline $\begin{array}{l}\text { Tuberculosis in } 32 \text { year old Asian on } \\
\text { radiographic appearances }\end{array}$ & $\begin{array}{l}\text { Rib excised after no response to } 7 \text { months' } \\
\text { antituberculous chemotherapy; fibrous } \\
\text { dysplasia diagnosed }\end{array}$ \\
\hline $\begin{array}{l}\text { Osteomyelitis in } 30 \text { year old woman on } \\
\text { clinical and radiological examination }\end{array}$ & $\begin{array}{l}\text { No response to } 4 \text { months of antibiotics; } \\
\text { biopsy showed reticulosarcoma and patient } \\
\text { died } 6 \text { months later }\end{array}$ \\
\hline \multicolumn{2}{|l|}{ STERNUM } \\
\hline $\begin{array}{l}\text { Chondroma in } 49 \text { year old woman on } \\
\text { radiological appearances }\end{array}$ & $\begin{array}{l}\text { Increasing pain and tumour size after } 2 \\
\text { months' observation; fibrosarcoma } \\
\text { subsequently diagnosed by biopsy-found } \\
\text { to be widely infiltrating; patient died } 7 \\
\text { months later. }\end{array}$ \\
\hline
\end{tabular}

Table 6 Cases in which the pathological diagnosis was changed by the bone tumour registry

\begin{tabular}{ll}
\hline $\begin{array}{l}\text { Diagnosis of } \\
\text { referring pathologist }\end{array}$ & $\begin{array}{l}\text { Definitive diagnosis of } \\
\text { bone tumour registry }\end{array}$ \\
\hline RIB & $\begin{array}{l}\text { Fibrous dysplasia } \\
\text { Fibrosarcoma } \\
\text { Osteosarcoma }\end{array}$ \\
$\begin{array}{l}\text { STERNUM } \\
\text { Chondrosarcoma }\end{array}$ & Hodgkin's lymphoma \\
$\begin{array}{l}\text { SCAPULA } \\
\text { Osteosarcoma }\end{array}$ & Fibrosarcoma \\
CLAVICLE & \\
$\begin{array}{l}\text { Osteoclastoma } \\
\text { SynOvial sarcoma }\end{array}$ & Lymphangioma \\
VERTEBRA & Clear cell sarcoma \\
Osteosarcoma & \\
\hline
\end{tabular}

with widely varying pathological diagnoses (table 1); malignant tumours were most common. In no case was the correct diagnosis made before excision and in two cases the preoperative radiograph showed no abnormality even though there was a palpable mass. Three of the eight patients died during the period of the study (mean interval to death seven months).

\section{Sternum}

There were nine malignant tumours and one benign tumour of the sternum (table 1). Chondrosarcoma was the most common diagnosis (six patients).

Most patients presented with a palpable mass rather than chest pain. The preoperative diagnosis was made correctly in only one case of chondrosarcoma and only six of the nine preoperative radiographs were reported as abnormal. Resection in these latter cases was performed for pain or for a palpable mass.

Six lesions were biopsied before definitive treatment. Seven lesions were treated by subtotal sternectomy and four patients received chemotherapy or radiotherapy. In five cases the tumour (including one chondroma) recurred. Six patients died of tumour related causes, including five with a chondrosarcoma (mean interval to death 3.3 months).

\section{Thoracic vertebrae}

Ten patients had a primary tumour of the thoracic vertebrae (table 1 ). Benign tumours were more common and there was a variety of tumour types. Seven tumours occurred in the lower six vertebrae and three in the upper six.

Six patients presented with local or radicular pain and only one with a palpable mass. Four patients subsequently developed myelopathy.

Resection was attempted in eight patients and six received adjuvant radiotherapy or chemotherapy. Tumour recurrence was detected in two patients (osteoblastoma and osteoclastoma). There were two tumour related deaths, two months and seven years from diagnosis (table 3 ).

\section{AGE DISTRIBUTION}

The age distribution of the tumours is shown in table 4. In patients under 45 years benign and malignant tumours occurred with almost equal frequency (28 $v 25)$. Most (29/37, 78\%) of the tumours in patients over 45 years were malignant.

Eosinophilic granuloma was the most common diagnosis in childhood, fibrous dysplasia and plasmacytoma in the middle age group, and chondrosarcoma in the older patients.

\section{DIAGNOSTIC ACCURACY}

The correct preoperative diagnosis was made on clinical or radiological findings (or both) in only seven patients. Relatively few lesions were diagnosed correctly from the radiographic appearances-benign lesions in four patients, chondrosarcoma in two (in the sternum and the scapula), and osteosarcoma of the scapula in one. In seven cases the diagnosis made by preoperative examination was incorrect and resulted in suboptimal management, possibly affecting survival (table 5). A preliminary biopsy was performed in only 41 cases-that is, definitive treatment was undertaken on the basis of clinical findings alone in 49 of the 90 cases (54\%).

In most cases the histological diagnosis made by the referring pathologist was confirmed subsequently by the bone tumour registry. In seven cases, however, the diagnosis of the tumour registry differed from the original diagnosis, with important clinical implications (table 6).

\section{Discussion}

Bone tumour registries have been established in several centres since the first was established 
by Codman in 1922,5 so that clinical, radiological, and histological data may be collected prospectively. This results in improved diagnostic accuracy in individual cases but computation of accurate incidence and prevalence rates is often impossible still because submission of information remains voluntary. The integration of pathology services in our region makes it most unlikely that appreciable numbers of tumours have not been notified to the registry.

Primary bone tumours of the thoracic skeleton are less common than metastatic and soft tissue tumours. ${ }^{6}$ Few large series have been published ${ }^{124}$ and often individual bones ${ }^{3}$ or a single tumour type have been considered. ${ }^{78} \mathrm{We}$ have included all the bones of the thoracic skeleton-that is, sternum, ribs, scapulae, clavicles, and thoracic vertebrae-as they are affected by similar types of tumours that present in a similar manner.

Differences were observed in the frequency of various tumours between our registry series and previously published series. For example, in our series, like that of Sabanathan et al, ${ }^{9}$ half the rib tumours were malignant and half benign, ${ }^{9}$ whereas other authors have reported a predominance of either malignant ${ }^{1}$ or benign $^{234}$ lesions. The overall predominance of malignant lesions in our series was due to the high proportion of malignant tumours in the scapulae (21 of 29) and sternum (9 of 10)-a pattern similar to that found by Dahlin et al. ${ }^{10}$ In our series as in other large series, ${ }^{911}$ chondrosarcoma was the most common tumour in the thoracic skeleton. The relative mortality rates of the major malignant tumours show that their behaviour in the thoracic skeleton is similar to that in the rest of the skeleton. Chondrosarcoma tends to run a slower clinical course, with a better prognosis than osteosarcoma. ${ }^{12}$

As expected from previous reports, ${ }^{12} 13$ eosinophilic granuloma and Ewing's sarcoma were exclusively tumours of childhood and adolescence. Fibrous dysplasia occurred predominantly in the middle age group but, unusually for a condition that develops in childhood and adolescence, one patient was 64 years at the time of presentation. In the older population chondrosarcoma and osteosarcoma predominated. Although in the skeleton as a whole osteosarcoma tends to occur at an earlier age than chondrosarcoma, ${ }^{12}$ this was not seen in the thorax. The peak incidence of osteosarcoma of the long bones is in adolescence. ${ }^{14}$

Chondrosarcoma should not necessarily be considered as a tumour that occurs only in patients beyond middle age, because in this series it was the most common chest wall tumour in young people aged $16-30$ years and eight of the 22 cases occurred in patients under 45 years of age. This may be an artefact related to the relatively small numbers but, more probably, may be explained by the fact that four of these eight cases arose in pre-existing osteochrondroma.

The mode of presentation provided no real guide to the benign or malignant nature of a lesion; $91 \%$ of benign tumours and $48 \%$ of malignant lesions presented with pain.

The number of tumours that presented in symptomless patients as an abnormal finding on a chest radiograph was much lower than that reported by Ala-Kulju et al, ${ }^{3}$ who found $60 \%$ of rib tumours to be in symptomless people. The difference may reflect the relative lack of mass screening in our region, but diagnosis depends on an active awareness of the possibility of discovering asymptomatic lesions in this context.

The difficulty of preoperative diagnosis of thoracic bone tumours is shown by our observation that the correct diagnosis was made by clinical and radiological methods in only seven patients. A biopsy was performed before definitive treatment in 41 cases but in six patients no histological confirmation was obtained to support the presumptive radiological diagnosis. The danger of this approach is shown by the subsequent discovery of malignant lesions in five patients when excision was eventually performed (table 5). We believe that biopsy of any suspected bone tumour of the thoracic skeleton is mandatory.

This review confirms the recognised difficulty ${ }^{15}$ in obtaining an accurate pathological diagnosis of bone tumours and seven diagnoses were modified by the bone tumour registry (table 6). Previous studies ${ }^{16}$ have reported that the prognosis of up to $8.5 \%$ of patients had been adversely affected by an error in the original pathological diagnosis. An adequate biopsy specimen, obtained at the time of presentation, should be referred to a specialist pathologist or tumour panel for optimum management.

The present survey has not been concerned with the results of treatment as recorded in the registry because no consistent therapeutic programmes were administered (table 3), owing to the large time span over which cases were recorded, the heterogeneity of the tumour types and sites, and the number of different clinicians who contributed data.

From time to time some tumour types are reclassified as newer investigative techniques become available. Five yearly review of cases, as practised by the Leeds bone tumour registry, enables recognition of new entities and permits account to be taken of changes in nomenclature.

This audit of data gathered prospectively from over 2004 primary bone tumours documents the clinical details of the uncommon group arising in the thoracic skeleton. Increased awareness of the causes of local chest pain and prompt biopsy of suspicious lesions are prerequisites for improved management of these patients.

We gratefully thank Dr G J Hardy, consultant pathologist, for We gratefully thank $D r$ G granting us access to the Leeds regional bone tumour
files and Mrs Helen Radcliffe for secretarial assistance.

1 Pascuzzi CA, Dahlin DC, Claggett OT. Primary tumours of the ribs and sternum. Surg Gyaecol Obstet 1957;104: $390-400$.

2 Teitelbaum SL. Twenty year's experience with intrinsic tumours of the bony thorax at a large institution. $J$ Thorac Cardiovasc Surg 1972;63:776-82. 
3 Ala-Kulju K, Ketonen P, Jarvinen A, et al. Primary tumours of the ribs. Scand J Thorac Cardiovasc Surg 1988;22: 97-100.

4 Ochsner A, Lucas GL, McFarland GB. Tumours of the thoracic skeleton: review of 134 cases. J Thorac Cardiovasc Surg 1966;52:311-21.

5 Luck JV, Monsen DCG. Bone tumours and tumour-like lesions of vertebrae. In: Ruge D, Wiltse LL, eds. Spinal disorders: diagnosis and treatment. Philadelphia: Lee and Febiger, 1979:274-86.

6 King RM, Pairolero PC, Trastek VF, et al. Primary chest wall tumours: factors affecting survival. Ann Thorac Surg 1986;41:597-601.

7 McAfee MK, Pairolero PC, Bergstralli EJ, et al. Chondrosarcoma of the chest wall: factors affecting survival. Ann Thorac Surg 1985;40:535-41.

8 Sabanathan S, Salama F. Cartilaginous tumours of the ribs. JR Coll Surg Edinb 1984;29:363-6.

9 Sabanathan S, Salama FD, Morgan WE, Harvey JA.
Primary chest wall tumours. Ann Thorac Surg 1985;39: 4-15.

10 Dahlin DC. Bone tumours: general aspects and data on 8542 cases. 4th ed. Springfield, Illinois: Thomas, 1986.

11 O'Neal LW, Ackerman LV. Cartilaginous tumours of ribs and sternum. J Thorac Surg 1951;21:71-108.

12 Lichtenstein L. Bone tumors. 5th ed. St Louis: Mosby, 1977:270.

13 McGarvan MH, Spady HA. Eosinophilic granuloma of bone: a study of twenty-eight cases. J Bone Joint Sur 1960;42A:979-92.

14 Larsson SE, Lorentzon $R$. The incidence of malignan primary bone tumours in relation to age, sex and site. $J$ Bone Joint Surg 1974;56B:534-40.

15 Barrett NR. Primary tumours of rib. Br J Surg 1955;43: 113-32.

16 Mankin HJ, Lange TA, Spanier SS. The hazards of biopsy in patients with malignant primary bone and soft tissue tumours. J Bone Joint Surg 1982;64A:1121-7. 